\title{
Variation on Photosynthetic Performance in Kiwifruit Seedling During Drought Stress and Rewatering
}

\author{
Yong Zhang1, a, Qiyang Chen"1, 2, b, Haoru Tang 1, c, * \\ ${ }^{1}$ College of Horticulture, Sichuan Agricultural University, 611130 Chengdu, China; \\ ${ }^{2}$ Key Laboratory of Horticulture Science for Southern Mountainous Regions, Ministry of Education, \\ College of Horticulture and Landscape Architecture, Southwest University, Chongqing 400715, \\ China. \\ a zhyong@sicau.edu.cn, b452547784@qq.com, , c chtang@sicau.edu.cn
}

Keywords: kiwifruit, drought stress, photosynthetic performance.

\begin{abstract}
Drought stress adversely impact on the global crop growth and productivity. It is especially important to elucidate the physiological characteristics on plants under drought stress. With the prolongation of drought time, chlorophyll content continued to decline. Root activity increased significantly in mild and moderate drought periods, rapid decline in severe drought period; leaf net photosynthetic rate $\left(\mathrm{P}_{\mathrm{n}}\right)$, transpiration rate $\left(\mathrm{T}_{\mathrm{r}}\right)$, stomatal conductance $\left(\mathrm{G}_{\mathrm{s}}\right)$ and photochemical efficiency ( $\Phi$ PS II ) decreased significantly with the increase of drought, while the intercellular $\mathrm{CO}_{2}$ concentration increased significantly. After 7 days of rehydration, there were different degrees of recovery. In mild and moderate drought periods, 'Hong yang' kiwifruit were resistant to drought by reducing the photosynthetic rate.
\end{abstract}

\section{Introduction}

At present, 1/3 of the world's land area is in arid or semi-arid state, and drought due to insufficient precipitation or precipitation patterns is the most devastating in many abiotic stresses and an important impact on crop yields Factors, each year due to drought lead to crop yields of more than $50 \%[1,2]$. The mechanism of plant resistance to drought is complex and diverse. Under drought stress, the morphological structure of plant is changed, the growth is inhibited and the photosynthetic rate is decreased [3]. Drought stress under the root growth was inhibited [4], plant leaves will be wilting, curl, due to smaller leaf area and reduce transpiration, severe yellowing off, so that the growth of plant parts of the ground is inhibited, root and shoot ratio increased [5]. Studies have shown that, kiwi tree flower bud differentiation period, moderate drought is conducive to fruit trees as soon as possible to stop growth of the shoots, conducive to flower bud differentiation [6]. However, when the drought is serious, the root absorption capacity is weakened, the photosynthetic efficiency of the leaves is reduced, the respiration of the fruit trees is strengthened, and the nutrient accumulation is reduced. The results showed that the photosynthetic PSII system of kiwifruit was affected under drought stress, but the light damage was completely restored after rapid rewatering. Kiwifruit transpiration rate is very sensitive to water deficit, and the severity of drought clearly affects photosynthesis $[7,8]$.

In this study, the effects of drought stress and rewatering on the photosynthesis characteristics of 'Hong yang' kiwifruit seedlings were studied in order to reveal the adaptability of 'Hong yang' kiwifruit to drought. And physiological response mechanism, which provided the theoretical basis for the cultivation of 'Hong yang' kiwifruit and the breeding of future breeds.

\section{Materials and Method}

\subsection{Plant Material and Drought Treatment}

Kiwifruit 'Hong yang' (Actinidia chinensis) seedlings were grown in the plastic pots in the chamber with vermiculite and turfy soil (1:3) at the experimental farm of Sichuan Agricultural University, 
Chengdu $\left(30^{\circ} 67^{\prime} \mathrm{N}, 104^{\circ} 06^{\prime} \mathrm{E}\right)$, Sichuan Province. Conduct a full irrigation before the treatment began, then stopped for a duration of irrigation water loss, 7 water treatments were set up to treat three days as a treatment period. After the water supply was stopped, the treatments were continued for $0 \mathrm{~d}$ (D0), 3d (D1), 6d (D2), 9d (D3), 12d (D4), 15d (D5) And rehydration after drought 7d (R1), five replicates for each treatment. The soil relative water content (SRWC) was measured daily with soil moisture meter HH2 (ML2x, GBR, En g land). We divided them into three groups according to the soil relative water content: normal (D0, R1: SRWC> 50\%), Mild drought (D1: 40\% <SRWC <50\%), moderate drought (D2, D3: 30\% <SRWC <40\%) and severe drought (D4, D5: SRWC <30\%). The photosynthetic parameters of each treatment plant were determined. Meanwhile, the measured plants were directly brought back to the laboratory for determination of related physiological indexes.

\subsection{Gas Exchange Parameters}

The functional leaves of 'Hong yang' seedlings with different unfurling directions were selected and net photosynthetic rate $\left(P_{n}\right)$ was measured by Li-6400 portable photosynthesis system (LI-cor, USA) on sunny days from 8:00 to 11:00. Stomatal conductance $\left(G_{s}\right)$, intercellular carbon dioxide concentration $\left(C_{i}\right)$, transpiration rate $\left(T_{r}\right)$, three replications.

\subsection{Chlorophyll Fluorescence Characteristics}

The initial fluorescence $\left(F_{0}\right)$ was measured with a $600 \mathrm{HZ}$ light and the maximum fluorescence $\left(F_{m}\right)$ was measured with a $3000 \mathrm{HZ}$ saturated pulsed light using a PAM-2100 modulated chlorophyll fluorescence instrument (WAIZ, Germany) for $30 \mathrm{~min}$ after the dark adaptation time. The maximum photochemical efficiency of PS II (Photosystem II) was $\left(F_{v} / F_{m}\right)$, three replications.

\subsection{Data Analysis}

Excel 2007 was used for data collation and charting, and SPSS19.0 statistical analysis software for one-way ANOVA, moreover least significant difference (LSD) was used for multiple comparisons.

\section{Results}

\subsection{Variation on Gas Exchange Parameters of 'Hong Yang' Seedling Leaves}

As can be seen from Fig. $1, P_{\mathrm{n}}, T_{\mathrm{r}}$ and $G_{\mathrm{s}}$ decreased significantly $(\mathrm{P}<0.05)$ and decreased to the lowest level during the later period of severe drought as compared with the control (D0), decreasing $64.5 \%, 63.2 \%$ and $51.3 \%$, Rehydration increased after 7 days, but significantly lower than the control level, indicating that the drought on 'Hong yang' kiwifruit photosynthetic system. (Fig. 1B, 1C and 1D) As the stress level aggravated, the intercellular $\mathrm{CO}_{2}$ concentration continued to rise, which increased by $14.3 \%-42.7 \%$ compared with $\mathrm{D} 0$. After rehydration treatment (R1), the $\mathrm{CO}_{2}$ concentration returned to D0 level basically (Fig. 1A). 

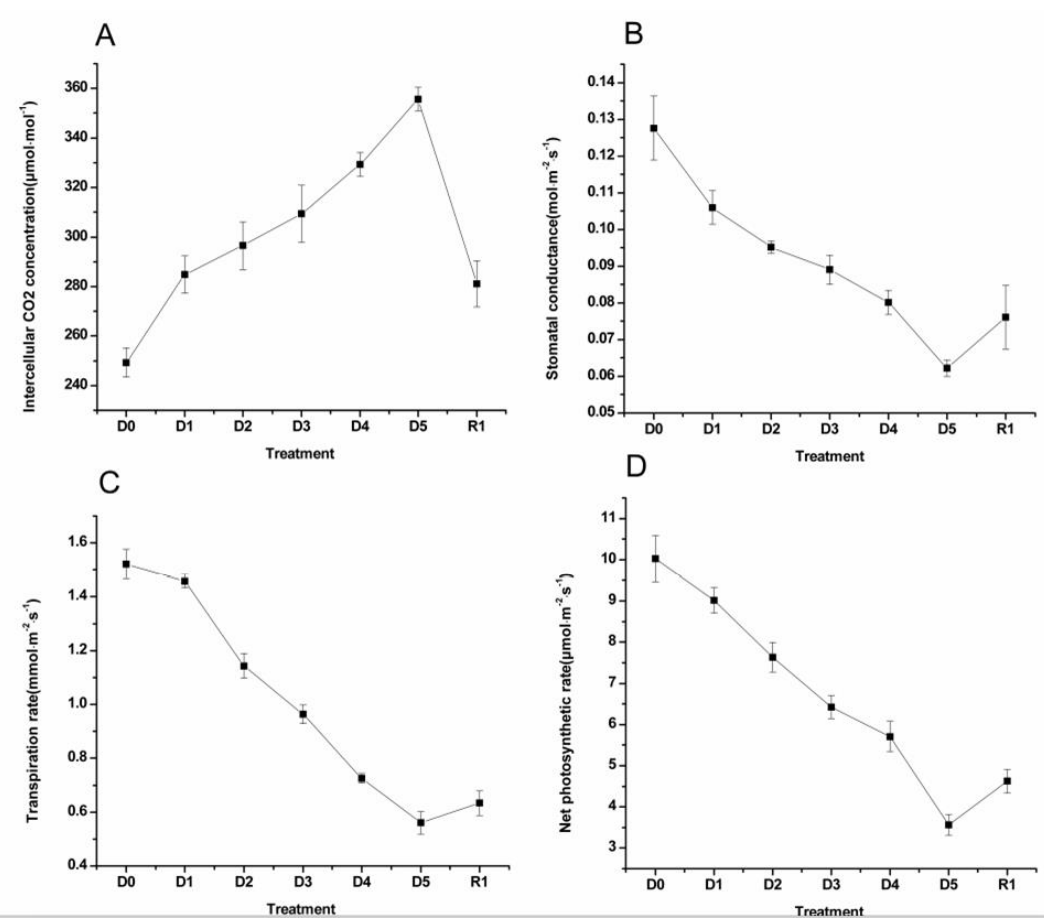

Fig. 1. Variation on gas exchange parameters

\subsection{Variation on Chlorophyll Fluorescence Characteristics of 'Hong Yang' Seedling Leaves}

The maximum photochemical quantum yield of $\Phi$ PS II, $F_{\mathrm{v}} / F_{\mathrm{m}}$ value is an indicator of the maximum light energy conversion efficiency in the PSII reaction center. The photochemical efficiency declined sharply at the late stage of moderate stress, reaching a decline of $77.3 \%$, and the photochemical efficiency under severe drought was always at a low level. After 7 days of rehydration, the $F_{\mathrm{v}} / F_{\mathrm{m}}$ value increased significantly but failed to recover completely to the control level (Figure 2).
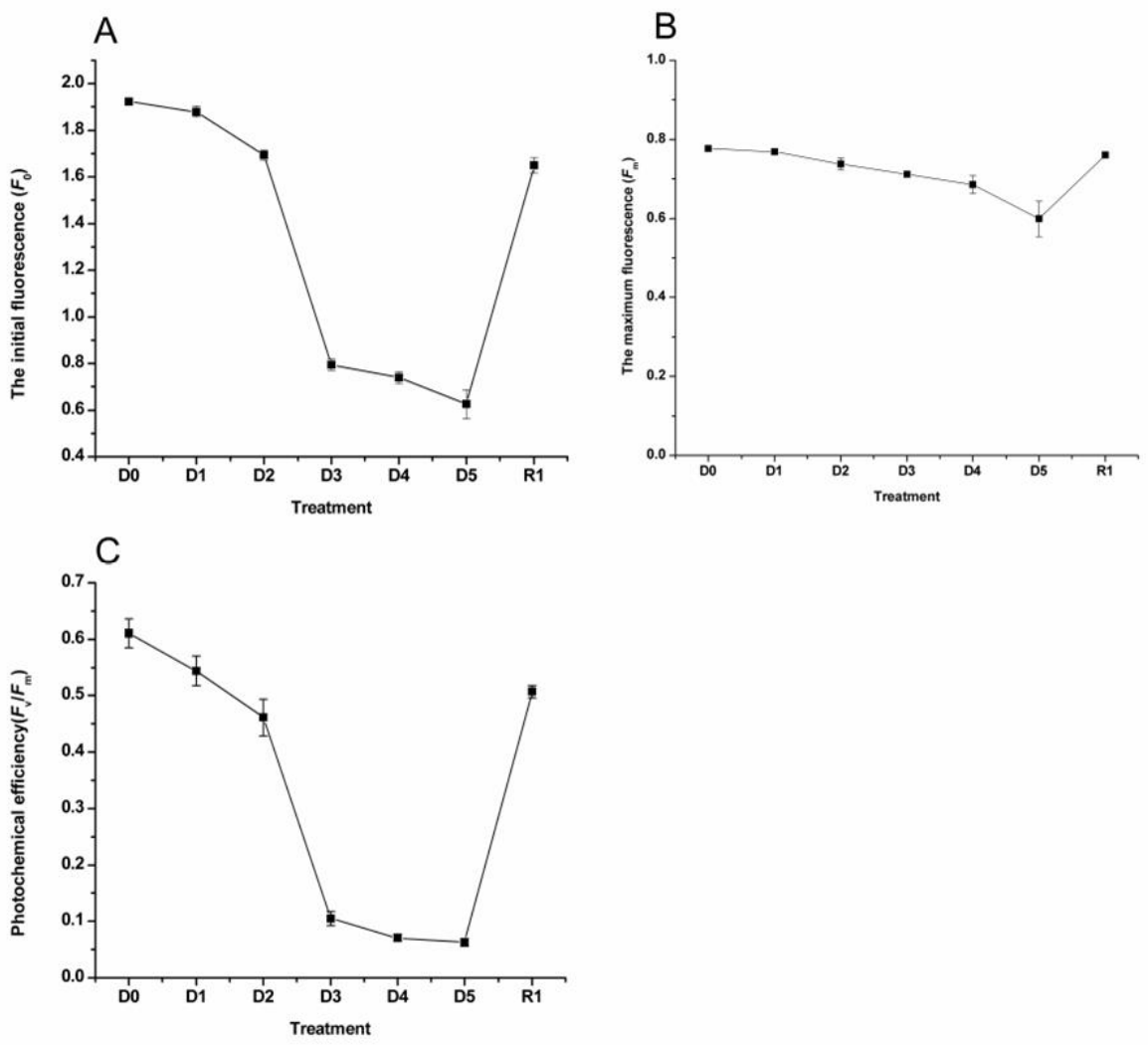

Fig. 2. Variation on chlorophyll fluorescence characteristics 


\section{Discussion and Conclusion}

Drought led to the growth and development of all organs of the tree obstructed, dysfunction, nutrient absorption, transport and synthesis of transformation cannot be normal, so that photosynthesis, transpiration, respiratory effects greatly diminished, or even stopped [6]. Photosynthesis is one of the most important physiological activities of plants and one of the most sensitive physiological processes to drought stress. Photosynthesis rate of plants under drought stress is decreased [9]. In this study, we found that the $P_{n}, T_{r}, G_{s}$ and photochemical efficiency ( PS II ) decreased with the increasing degree of stress, because the decrease of LRWC would lead to stomatal closure and decrease of stomatal conductance [10]. While $C_{i}$ showed an upward trend. The reason for the increase may be that the photosynthesis is decreased and the respiration is strengthened, which leads to the increase of $\mathrm{CO}_{2}$ concentration. In severe drought, the stomatal limitation and non-stomatal limitation work together, while the late non-stomatal limitation is the main factor for the decrease of photosynthetic rate Factors, at this time kiwi leaves photosynthetic system severely damaged.

\section{References}

[1]. Toker C, Canci H, Yildirim T. Evaluation of perennial wild Cicer species for drought resistance. Genetic Resources \& Crop Evolution.Vol. 54 (2007) No. 8, p. 1781-1786.

[2]. Tuberosa R, Salvi S. Genomics approaches to improve drought tolerance in crops. Trends in Plant Science. Vol. 11 (2006) No. 8, p. 405-412.

[3]. Yao X, Chu J, Wang G. Effects of drought stress and selenium supply on growth and physiological characteristics of wheat seedlings. Acta Physiologiae Plantarum. Vol. 31 (2009) No. 5, p. 1031-1036.

[4]. Kato Y, Okami M. Root growth dynamics and stomatal behaviour of rice (Oryza sativa L.) grown under aerobic and flooded conditions. Field Crops Research. Vol. 117 (2010) No. 1, p. 9-17.

[5]. Kong F. Progress on the Crop Response Mechanism to Drought Stress. Agricultural Science \& Technology and Equipment. Vol. 235 (2014) No. 1, p. 3-4.

[6]. Zou X L, Yan X L, Ji W L. Effects of high temperature and drought on the mountain Kiwifruit Growth and Development and Defense Measures. Modern Horticulture. Vol. 20 (2015) No. 3, p. 24-25.

[7]. Riccado G, Rossano M, Cristos X, et al. The effect of drought and vapour pressure deficit on gas exchange of young kiwifruit (Actinidia deliciosa) vines. Annals of Botany. Vol. 77 (1996) No. 6, p. 605-613.

[8]. Montanaro G, Dichio B, Xiloyannis C. Response of photosynthetic machinery of field-grown kiwifruit under Mediterranean conditions during drought and re-watering. Photosynthetica. Vol. 45 (2007) No. 4, p. 533-540.

[9]. Haldimann P, Feller U. Photosynthetic perform-ance and water relations in young pubescent oak (Quercus pubescens) trees during drought stress and recovery. New Phytologist. Vol. 174 (2007) No. 4, p. 799-810.

[10]. Meeteren U V, Nejad A R, Harbinson J, et al. Effect of (changes in) air humidity on transpiration and (adaptation of) stomatal closure of Tradescantia leaves during water stress. Acta Horticulturae. Vol. 847 (2009), p. 115-122. 